\title{
RESENHA
}

\section{O ENSINO DE CONCEITOS E TEORIAS MATEMÁTICAS: uma aliança possível entre a investigação e a história}

\author{
José Ricardo e Souza Mafra ${ }^{74}$ \\ Girlane Aires Gonçalves75
}

\begin{abstract}
MENDES, I. A. Investigação Histórica no Ensino de Matemática. Rio de Janeiro: Editora Ciência Moderna Ltda, 2009. 256 p. ISBN 978-85-7393-827-2
\end{abstract}

Lançado em 2009, pela Editora Ciência Moderna, o livro "Investigação Histórica no Ensino de Matemática" surge a partir dos estudos e pesquisas desenvolvidas pelo autor, ao longo de três décadas, sobre a História da Matemática e suas relações com Educação, mais especificamente o campo da Educação Matemática. Logo na apresentação do livro é possível verificarmos o eixo norteador principal da temática discutida na obra: a relação entre a história da matemática, cognição e aprendizagem matemática via suporte de encaminhamentos metodológicos, através da investigação histórica. Investigação aqui concebida como um delineamento de ações, conforme abordagens e situações pedagógicas apoiadas na história e na matemática, como um elemento gerador de discussões e reflexões em um cenário educacional cujo o foco central é o ensino de conceitos e teorias matemáticas.

Ao propor a investigação histórica, como uma fonte de aprendizagens e de potencial recurso pedagógico ao professor - para o trabalho envolvendo conceitos matemáticos - o autor parte do princípio de que, o

74 Doutorado em Educação pela Universidade Federal do Rio Grande do Norte. Professor Adjunto da Universidade Federal do Oeste do Pará. E-mail: jose.mafra@ufopa.edu.br.

75 Especialização em Metodologias no Ensino de Matemática e Física pela Universidade Internacional UNINTER. Professora do Instituto Esperança de Ensino Superior, IESPES, Brasil. Email: aires.grilane@gmail.com. 
tema em questão, ainda é pouco valorizado e problematizado na comunidade acadêmica, seja pelo desconhecimento da proposta, seja pela falta de oportunidade e dificuldades de implementação. Todavia, em seu percurso epistemológico de práticas, experiências e pesquisas educacionais - quase toda focada em estudos relacionados a história da matemática - o autor fornece depoimentos e registros, a partir dos grupos e partícipes de suas pesquisas, em geral professores e acadêmicos em cursos de formação primeira e continuada, para mostrar (e validar) a importância das informações históricas e como elas podem subsidiar os processos formativos, relacionados com a compreensão dos objetos matemáticos. Tal implicação possui uma consequência significativa em termos de conhecimentos a serem adquiridos: o entendimento de que a Matemática é um produto humano e de que os conhecimentos gerados em diferentes civilizações e contextos culturais, contribuíram, não apenas para aquele momento histórico e cultural em uma determinada sociedade, más, também, como estes conhecimentos, ao serem difundidos e disseminados, foram sendo incorporados a outras formas de pensar matematicamente, originado elementos agregadores de informações simbólicas, até chegar ao que conhecemos hoje como Matemática.

A obra é composta por seis capítulos na qual o autor tece as suas considerações relativas ao foco de discussão do proposto, ou seja, a Investigação Histórica sugerida no título da obra. Assim sendo, o capítulo inicial aponta um panorama geral sobre as impressões e conexões entre os aspectos históricos e possíveis relações a serem estabelecidas com o ensino de matemática. Fornece indicadores de validação da proposta em função da discussão e implementação inicial de uma proposta metodológica de ensino, aliando a história e a matemática, em cursos de formação ministrados, através de uma importante ferramenta do pensar e da aprendizagem: a investigação. Assim, a obra fornece elementos para se pensar o conhecimento histórico como um princípio inicial e unificador de percepções e valores, na reconstrução de momentos históricos, tendo por 
base informações de fontes históricas cuja compreensão nos permita fornecer uma espécie de elementos gerador da aprendizagem da Matemática.

Ainda no capítulo inicial, são apresentados alguns pressupostos de validação do estudo, com base na compreensão inicial das origens formativas do conhecimento matemático e, particularmente, como se dá o entendimento destes processos, na visão de teóricos como D'Ambrosio, Von Glasersfeld e Skemp na busca de uma concepção, defendida pelo autor, em que o estudante procure, na história, a fonte de reflexões sobre o conhecimento e sua disseminação, via investigação. Esta concepção, estaria assim direcionada aos processos de aprendizagens da matemática, através de um conjunto de atividades previstas, visando a formulação de conceitos, inferências matemáticas e o estudo dos objetos matemáticos.

No capítulo 2 (dois) o autor fornece a base teórica para se pensar como a produção do conhecimento matemático permite um entendimento inicial de como ocorre os processos de criação e difusão das ideias matemáticas. Discute especialmente os aspectos metodológicos e epistemológicos que cercam e delineiam a Matemática, tendo em vista sua argumentação favorável ao uso da investigação histórica como vetor de produção de conhecimentos no cotidiano escolar. Fornece indicadores sugestivos de atividades em que exemplifica a articulação entre informações históricas (mensuração de objetos pela sombra e os relógios de sol) e o desenvolvimento de conceitos (por exemplo, a noção de proporcionalidade) e habilidades conceituais de aspectos matemáticos (por exemplo, semelhanças de triângulos), diretamente conectados com as situações cotidianas apresentadas. Tal inferência, é discutida pelo autor, com base em Dreyfus e Fischbein, como um fator relacionado aos processos cognitivos envolvidos no pensamento escolar e sua articulação com o pensamento matemático, no processo de geração das abstrações. Encerrando o capítulo, o autor, potencializa suas inferências na busca de uma matriz dimensional, na qual possa integrar a perspectiva construtiva do 
conhecimento matemático e uma perspectiva construtiva em educação matemática, projetada em ações (atividades) investigativas para o ensino de conceitos matemáticos. Tendo por base, Dockweiller, o autor propõe o dimensionamento de atividades auto-orientadas, visando o aprimoramento de aspectos construtivos. Assim, a busca de uma continuidade, em termos de construções conceituais, com base em aspectos manipulativos, pode ser projetada, a medida em que o aluno se envolve com o objeto a ser conhecido, desencadeando assim um processo de abstração.

No capítulo 3 (três) o autor continua sua linha argumentativa de uso das investigações históricas no ensino da matemática, com base na função da história na construção da Matemática. Argumenta e apresenta alguns mecanismos históricos de como o conhecimento matemático foi elaborado e disseminado ao longo das diferentes culturas (por exemplo, a trigonometria) possibilitando assim, uma reflexão sobre como os fatos históricos são construídos e difundidos, na forma de versões, adaptações e interpretações de, por exemplo, situações e problemas matemáticos. O autor alerta, com base em sua experiência profissional e de pesquisa, para a necessidade de que o professor, ao fazer uso da história da matemática em sala de aula, precisa ter um entendimento profundo da própria matemática. Finalizando o capítulo, apresenta-se um modelo alternativo para se pensar, como uma abordagem que agregue elementos de inferência inicial do conhecimento matemático pode ser potencializado via projetos de investigação histórica - conforme denominação do autor - indicando assim, tanto orientações para a ação docente, como propondo possíveis tópicos matemáticos a serem desenvolvidos.

Com base em seus pressupostos teóricos-metodológicos apresentados nos capítulos anteriores, são apresentadas, no capítulo 4 (quatro) propostas de atividades estruturadas, via investigação de informações históricas, na abordagem do ensino de matemática. O capítulo está distribuído em dois tópicos. No primeiro tópico, são apresentadas propostas de atividades, como forma de envolvimento em estudos com essa abordagem. Um dos 
assuntos explorados nesse tópico, por exemplo, versa sobre os conceitos de ângulo, características e tipologias. Mostra de forma introdutória, como o conceito e entendimento dos ângulos foram surgindo na história. Sugere uma estrutura metodológica de desenvolvimento da atividade e indica procedimentos e sugestões ao professor. O segundo tópico apresenta estudos históricos, como uma proposta de aprendizagem a partir da pesquisa educacional e documental. Alguns temas são propostos, como a circunferência e círculo, relações pitagóricas e o estudo dos triângulos numéricos, projetando um delineamento possível no encaminhamento proporcionado pelo docente, com base em estudos teóricos introdutórios e, de que forma, estes conceitos e teorias foram sendo desenvolvidos ao longo da História. Com base nestas informações, são sugeridos procedimentos, inferências e encaminhamentos pedagógicos, como forma de se trabalhar as informações matemáticas presentes nas fontes, via investigação histórica.

No capítulo 5 (cinco) são apresentadas as argumentações do autor, para a sustentação do modelo proposto, indicando recomendações e diretrizes de ordem metodológica e didática, para efeito de uma boa condução das atividades por parte do professor. Em que pese as dificuldades susceptíveis como, por exemplo, a dificuldade em encontrar fontes históricas primárias e sua complexidade de organização, o qual exigiria, por parte do professor, um esforço significativo em termos de planejamento, além de dificuldades inúmeras possíveis, em termos de implementação, a argumentação final projeta um ambiente e cenário educacional bastante promissor, em educação matemática.

Encerrando o livro, são apresentados no capítulo final, uma bibliografia sugestiva de fontes de referência a serem utilizadas em pesquisa educacional, sobre o tema, composta de bibliografia comentada, de forma a subsidiar a busca de fundamentos histórico-epistemológico pelo professor. Além disso, é fornecida uma lista de homepages sobre história da matemática que, embora desatualizada, fornece elementos para estudos e 
pesquisas sobre o tema, seguida de bibliografia consultada e referências bibliográficas.

A obra fornece indicadores consistentes de novos cenários educacionais, com base em pressupostos teórico-metodológicos pautados na história, matemática e elementos de investigação educacional. As propostas de atividades refletem possibilidades de percursos investigativos, articulados com a geração de conhecimento voltado para o ensino de conceitos e teorias matemáticas. Assim sendo, aponta caminhos e possibilidades de cenários investigativos, em que elementos da história e da matemática articulado com uma capacidade metodológica de ação pedagógica intrínseco aos conhecimentos matemáticos, permitem potencializar ações cognitivas. Estas ações convergiriam não apenas, se pensando no desenvolvimento de habilidades matemáticas, mas também na potencialização da criatividade, imaginação e produção de conhecimentos novos, o que, em tese, uma investigação educacional pode proporcionar, ao encaminhar uma proposta com estas dimensões.

Recebida em: Março de 2017 Aprovada em: Abril de 2017 